INDEPENDENT JOURNAL OF MANAGEMENT \& PRODUCTION (IJM\&P)

http://www.ijmp.jor.br

v. 6, n. 2, April - June 2015

ISSN: 2236-269X

DOI: 10.14807/ijmp.v6i2.250

\title{
A FUZZY LOGIC APPLICATION IN VIRTUAL EDUCATION
}

Thiago Drummond Moreira Universidade CEUMA, Brazil E-mail: thiagodr@gmail.com

Maria Augusta Soares Machado Faculdades IBMEC - RJ, Brazil E-mail: mmachado@ibmecrj.br

Submission: 02/07/2014

Revision: 16/07/2014

Accept: 10/11/2014

\section{ABSTRACT}

Traditionally, the teaching and learning process uses the problems resolving for fixing, transmitting and evaluating concepts and knowledge about a subject. Learning is the process of acquiring relative permanent changes in understanding, attitude, knowledge, information, capacity and ability through experience. A change can be decided or involuntary, to better or worsen learning. The learning process is an internal cognitive event. To help this teaching and learning process, it is important the use of a computer tool able to stimulate these changes. Also, it is important that it can function as validation and helping tool to the student. These functions are performed by computer systems called Intelligent Tutoring Systems. This paper describes the use of artificial intelligence techniques as a teaching support tool. Using Intelligent Tutoring Systems and fuzzy logic, this work shows, through electronic ways, teaching will be more efficient and more adapted to students necessities, in group or individually.

Keywords: Fuzzy Logic, Intelligent Tutoring Systems, Teaching and Learning. 
DOI: 10.14807/ijmp.v6i2.250

\section{INTRODUCTION}

Educational applications using the computer technology have been developed since the 60s. Initially, they were classified as Computer-Assisted Instruction and used the paradigm of programmed instruction, whose educational methods feature a focused exhibition in the form of a teacher. First, the students must understand the lesson given by the teacher to then answer any questions and, thus, strengthen their understanding. It means that, teaching can be readily caused by "schedules of reinforcement", that is, compensating for the behavior data desired time.

Over time, the theoretical perspectives of educational psychologists tended to migrate to cognitive psychology. According to Piaget (1973), most of what one learns is on their own initiative and in interaction with the reality that surrounds them. The students build their knowledge. This trend is also seen in the process of developing these CAI systems.

With the development of Artificial Intelligence ( $\mathrm{Al}$ ) techniques and research in the field of cognitive sciences, increased the degree of "intelligence" of CAI systems. They are named as ICAI ("intelligent" CAI) and later known as Intelligent Tutoring Systems. One of the main motivations for research in Artificial Intelligence in Education is the development of principles by which computational learning environments can be designed as places where students can have experiences that are essential and beneficial to them, regardless of their individual differences, experiences previous or other cognitive situations.

Thus, by modeling or mapping the students, these systems can customize the instruction, aligning the presentation with the level of students' knowledge and their learning content. Therefore, most systems with these characteristics present educational methods that provide a way of finding student-centered dialogues and tutorials which are basically determined by the conceptual knowledge and the learning behavior of the students (PARK, 1987). 


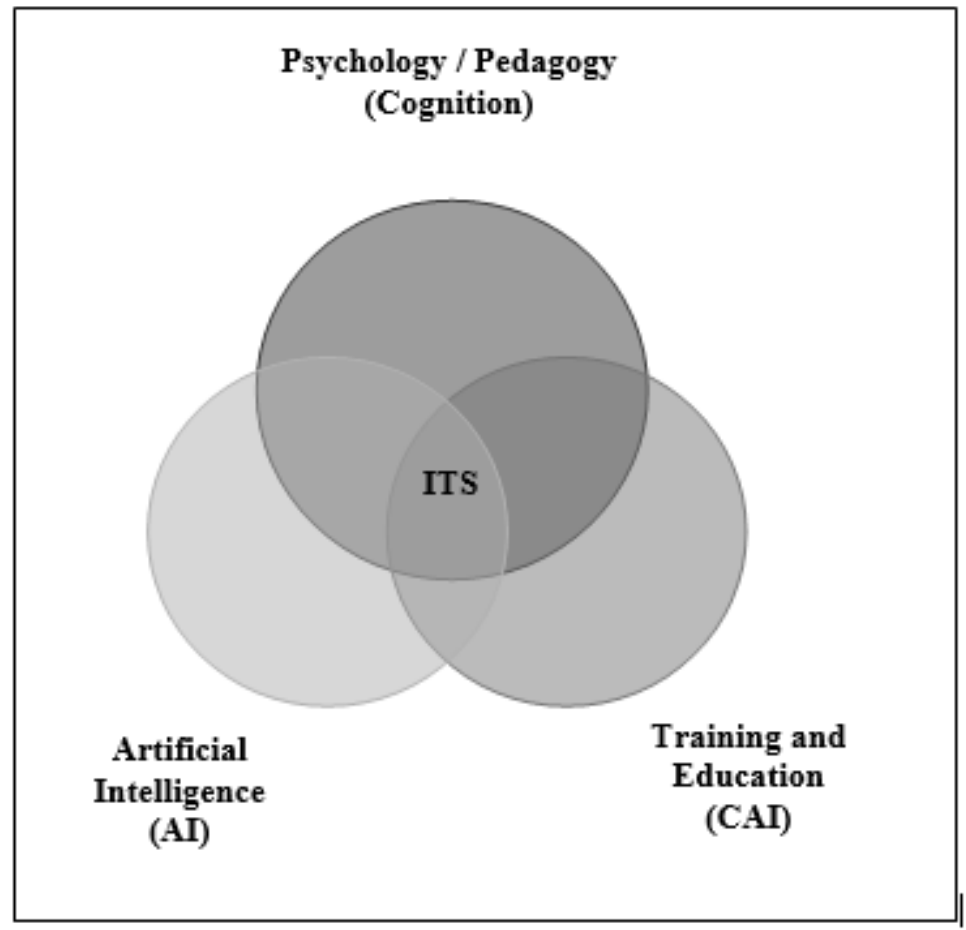

Figure 1: Field of intelligent tutoring applications

Currently, it is accepted that any system that has as its main objective the teaching function should incorporate principles of Al. These systems need to know the level of expertise of its members, and recognize which points in the domain of knowledge the student has evolved and which remains their weak points.

\section{INTELLIGENT TUTORING SYSTEMS}

Expert systems are computer programs designed to acquire and make available the knowledge of a human expert. Intelligent tutoring systems (ITSs) are expert systems applied to education which aim to assist student learning by simulating a tutor.

According to Fowler (1991), the ITSs are computer programs for educational purposes and incorporate Al techniques, usually using the technology of expert systems. The ITSs are derived from CAI programs and offer advantages over these because they can simulate the process of human thought within a given area, to assist in strategies in problem solving and in decision making.

Classified in accordance to Pozzebon and Barreto (2002), Intelligent tutoring systems derived from CAI programs (Computer Aided Instruction), which try to implement a generic model that can be used to teach any student. 
In researches of any educational system involving principles of $\mathrm{Al}$, the approach is somewhat different from that of the knowledge engineering in which the experts should represent, in a given domain, their strategies and decisions in the form of programs. Instead, the main purpose is to capture the knowledge necessary to enable experts compose an educational interaction. Instead of a decision, the result of knowledge is knowledge which itself is explicitly represented so it can be used. Therefore, it is also the responsibility of programs to compose educational interactions dynamically.

According to Jonassen (1993), ITSs must pass three tests before being considered "smart":

- The content of the topic or skill should be coded so that the system can access information, make inferences or solve problems.

- The system should be able to evaluate the acquisition of this knowledge by the student.

- Tutorial strategies should be designed to reduce the discrepancy between expert knowledge and knowledge of the student

It can be observed:

"[...] ITS are programs that modify their knowledge bases, realize interventions in the students learning and are endowed with the capacity to learn and adapt their teaching strategies through interaction with the students." (Cited by SCHMITZ VACCARI; LÓPEZ; FARACO; ROSATELLI, 2002, p. 3).

The ITSs are formed basically by four modules.

First Module - The model of the expert or domain model contains the stored expert knowledge on the subject being taught. This knowledge is acquired from an expert and should therefore be transferred to the students (SCHMITZ et. al., 2002). It is fundamentally a knowledge base containing information for a particular domain, which is organized in any way to represent the knowledge of an expert or teacher (POZZEBON; BAKER, 2002).

Second Module - The model of the guardian or pedagogical model is responsible for adopting different ways to expose a subject, making it understandable and interesting. In the statement of a body of knowledge to a person, different strategies 
and techniques are selected and dynamically combined in response to the attitudes and needs of students (POZZEBON; BAKER, 2002).

Third Module - The student model contains the information for each student who uses the system. This information is related to the level of student knowledge on the subject and their rate of learning (SCHMITZ; LOPEZ; ROSATELLI FARACO, 2002). The main feature of this model should include all aspects of knowledge and behavior student bring consequences for their performance and learning (POZZEBON; BARRETO, 2002). Perhaps, this is the most important module of an ITS. It is from the information contained in this model that all strategies, contents are exposed to tutor students through the model.

Fourth Module - The interface module is the communication channel between the ITS and the student (SCHMITZ et. al., 2002). In software engineering, the user interface has been the primary concern of designers when they are discussing the creation of a new application because, as stated by Hix and Hartson, "For users, the interface is the system itself." (POZZEBON; BARRETO, 2002).

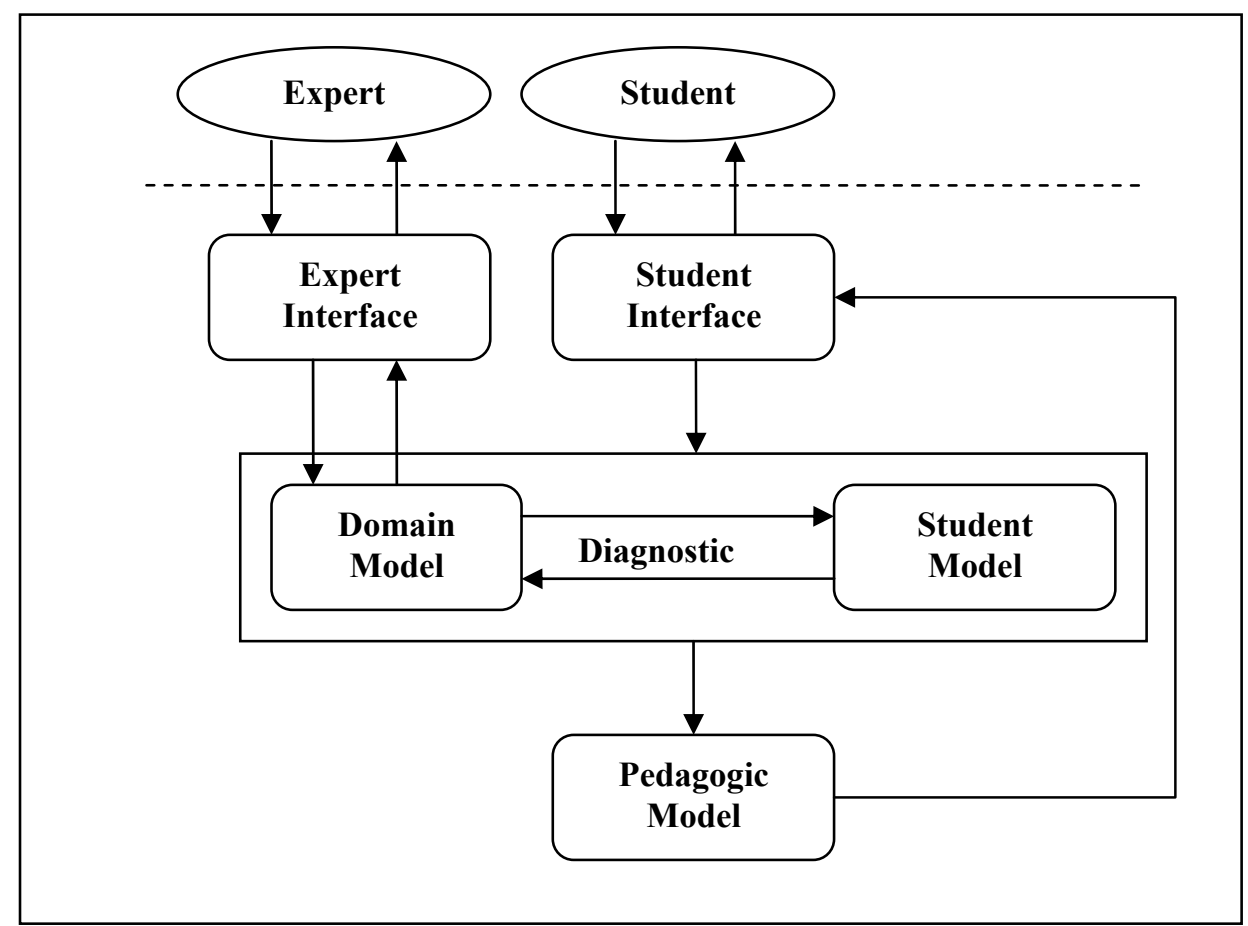

Figure 2: Basic architecture of an ITS

Through this architecture, it can be seen that the student has a greater chance to have a personalized learning. It will be up to the teacher to ask questions, 
perchance not solved by ITS, and support the student. Some advantages of intelligent tutorial systems could be:

"First, the computer finds it easier to retain the information and deliver it in a systematic, thorough and complete manner. The computer never forgets a detail, if this is specified in the program. A headache or a family problem never changes its performance. Second, this capability allows systematization of computer monitoring of the student in relation to the most frequent errors and the execution the tasks orders. Often the teacher has a lot of difficulty in performing this monitoring, so it can be done at a much more comprehensive way by the computer. Third, computer systems today have many multimedia features such as colors, animation and sound." [...] (VALENTE, 1997, p. 20).

\section{MULTIAGENT INTELLIGENT TUTORING SYSTEMS}

For distance learning, some authors claim that this is responsible for a mass without quality education. As has been seen, the intelligent tutoring systems are especially important in the customization of teaching the student. By joining this idea of Internet's ITSs, it can cause distance learning with higher quality. It is necessary to think of a new architecture of intelligent tutoring systems which can be individualized to the needs of each student and also be collective and collaborative with other learners.

An agent can be defined as an entity (human or artificial) physical or abstract that performs an action on something, either about the students or their environment, producing an effect (FERBER apud SICHMAN, 1992).

In this environment, students are divided into distinct environment in which areas are called cooperative groups. Basically, two types of interactions occur, intragroup interaction, where students learn by interacting and cooperating within their own groups with artificial agents and the teacher, and intergroup interaction that can occur between practitioners in various existing groups. These interactions occur through the use of multimedia and networks, intranets and internet technology.

The description of the architecture of a multi-agent learning environment is:

Tutor Agent - participates in all the activities of teaching and assessment. It controls the interactions of groups with the system during the process of teaching / learning. It is also responsible for presenting the knowledge to learners. 
Domain agents - are holders of certain knowledge, an expert. It is responsible for the storage and representation of specific knowledge, which is the only feature that differentiates one from another Domain Agent.

Modeling agents - responsible for the acquisition, representation and maintenance of the information about students and groups during the process of teaching / learning process.

Strategic agent - is responsible for defining pedagogical strategies to be adopted by the Tutor Agent from interaction with Modeling Agent, and after observing the behavior of each learner, that is, who decides what, when and content that will be presented to the students.

Agent Search - aims to provide the learner custom that can help you clear the doubts information. A set of intelligent mobile agents is instantiated to access remote data resources.

Teacher agent is a human agent noted for performing the roles of supervisor, evaluator and specialist.

Students' agents - are the users' target of the system. The good performance of them is the target to be reached.

Knowledge Engineer agent - is responsible for maintaining the Domain Agent, which includes the issue of knowledge of each organization and their domains.

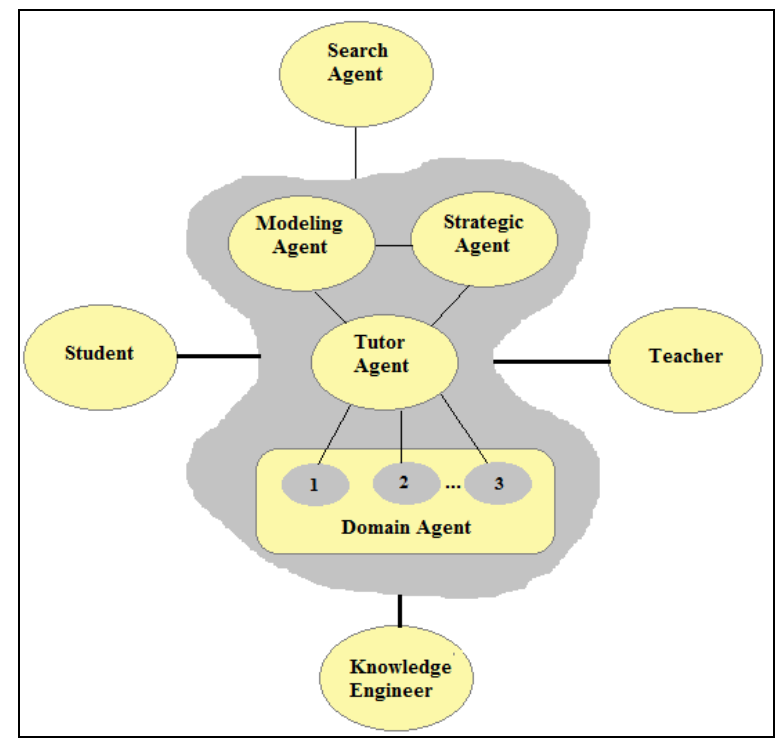

Figure 3: ITS Architecture Multiagent 


\section{FUZZY LOGIC}

About 2000 years ago, the use of Boolean logic (where an expression can only take two values, true or false) was a way of modeling mathematical problems. Conventional computer modeling uses this concept of ambivalence and therefore cannot work with ambiguities (MUKAIDONO cited by COSTA et al., 2003, p. 1).

This kind of modeling (can be written as reasoning), assuming a statement as true or false, is impossible when thinking about real-world problems. It is hard to imagine (if not impossible) for a person considering only two possibilities (yes / no, true / false, black / white) when dealing with factors such as ambiguities, uncertainties and vague information.

Trying to approximate the mathematical modeling and real-world problems, Zadeh recognized the many possibilities between true and false (after observing that many rules used by people to make inferences could not be explained by the people who used) and developed in 1965, a variation of traditional logic and fuzzy logic.

Different from Boolean logic, fuzzy (or diffuse) is a multivalued logic - instead of an element being $100 \%$ owned by one set or the other or a proposition wholly true or false, fuzzy logic works with partially true statements and partially false at the same time. In this context, Boolean logic becomes a particular case of fuzzy logic (BARBALHO, 2001, p. 20).

As an example, one can present the problem to identify people with average height. If we consider such people with a height between 1.60 and 1.70 meters, Boolean logic could not identify the people with 1.59 meters as belonging to this group. Already fuzzy logic identifies that person as belonging to the group, but with a lower degree of certainty that another person with 1.65 meters.

Therefore, one can define fuzzy logic as a tool capable of capturing vague information, generally described in natural language, and convert them to digital form for easy handling (WAGNER cited by COSTA et al., 2003, p. 3). The goal is to capture the different degrees of existing truth for real life situations and model them in a mathematical form. 


\subsection{Fuzzy Sets}

In classical set theory, the sets are defined as a collection of objects that have certain characteristics in common. These objects can be numbers, words, concepts, anything and have only two ways of relating to the set: either belong or not belong to the set.

When analyzing the problem of an average stature, one can see that people with 1.59 or 1.71 meters do not belong to the group of people with average height, since this set includes only people with heights between 1.60 and 1.70 meters. Although for obvious reasons, they must belong to this set.

Zadeh, to formulate the fuzzy set theory, was based on the classical theory of sets and presents that as a generalization of this. The sets are also defined on a domain (Universe of Discourse), but differ from those for not having a clearly defined boundary (apud BARBALHO; ZADEH, 2001, p. 20). It tries to translate, through formal mathematical representations, the inaccurate information from the real world.

The central idea is that an element belongs to a set with a certain degree of membership. In theory, this degree is presented as a Function of Relevance. This function maps each element of the universe with a number between 0 and 1 (in the classical theory, the degree of membership takes only the values 0 or 1). Thus, propositions are not only true or false, but range from completely false to completely true, through partially false and partially true.

According to Barbalho (2001), the representation of a fuzzy set is given by the ordered pair X, $\mu \mathrm{A}(\mathrm{X})$.

- $A=\{(X, \mu A(X)) \mid X € U\} ;$

- $\mathrm{X}$ is the variable being studied;

- $\mu \mathrm{A}(\mathrm{X})$ is a function which image belongs to the interval $[0,1]$;

-1" represents the concept of total relevance;

• "0" is not relevant.

\subsubsection{Membership Function}

Each fuzzy set, $A$, is defined in terms of relevance to a universal set, $X$, for a function called membership function, assigning each element a number $x, A(x)$ in the 
closed interval $[0,1]$ that characterizes the degree of membership of $x$ in $A$. The membership function has the form: $\mathrm{A}: \mathrm{x}[0,1]$.

Shaw (1999) states that a membership function is a function that assigns numeric degrees of membership for discrete values of a variable in their universe of discourse.

According Barbalho (2001), any function that maps the domain $U$ in the interval $[0,1]$ can be used as membership function. In practice, however, the triangular and trapezoidal forms (figure 4), the simplicity of representation, are the most frequently used.

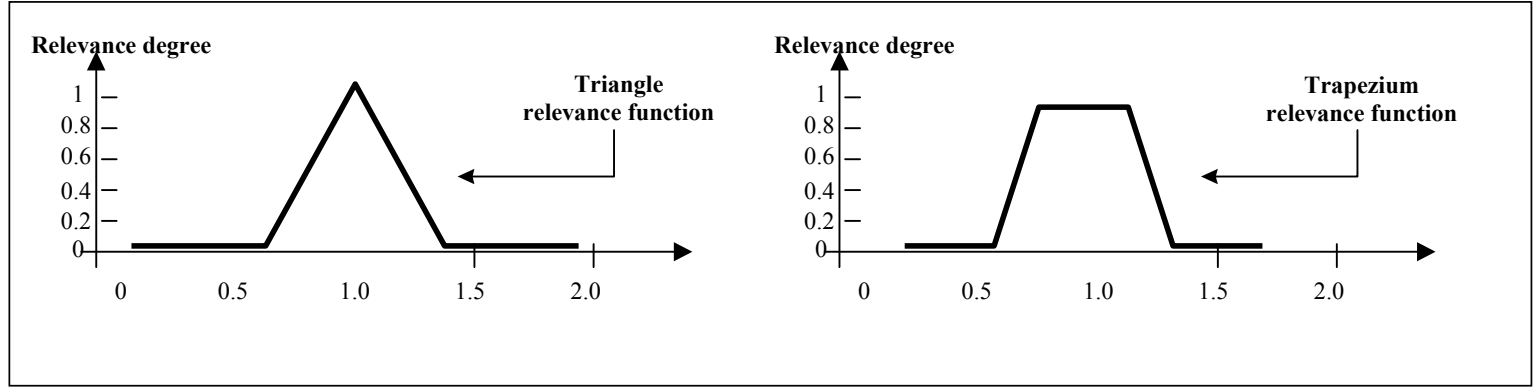

Figure 4: Relevance Functions

\subsection{Systems Based In Fuzzy Rules}

Most computer systems have their knowledge represented by rules that dictate how they should act. This representation is used for a long time, such as an ITS that has its bases (modules described in the previous section) formed through rules.

Systems using fuzzy logic are not different. Their behaviors are also dictated by rules. However, the rules used by them are called fuzzy rules. The fuzzy rules are characterized by a conditional expression of the form: IF < fuzzy antecedent expression THEN < fuzzy consequent-expression.

According to Barbalho (2001), the antecedent is formed by a single proposition or a combination of propositions and describes conditions found by the rule. And the consequent describes an action to be taken in the case of all of the foregoing propositions to be answered. The combination of propositions is done through the logical operators "AND" and "OR". 
An example: "IF a very drunk man and age less than 18 years THEN contact the juvenile court." We demonstrated, by example, that the understanding of some points is still needed:

- Linguistic variables versus numerical values of the variables (age versus 18 years) are interpreted using fuzzy logic.

- Linguistic variables intensity (drunk can have a finite number of linguistic terms associated with it, they can go from extremely drunk to not even drunk), can also be interpreted by fuzzy logic.

- When the antecedents have combinations of fuzzy propositions, or fuzzy rules, (associated with degrees of membership), the degree of membership of the consequent depends on the antecedent.

\subsection{Fuzzy Inference Systems}

According to Wagner (quoted in COSTA et al., 2003), fuzzy inference systems are based on fuzzy inference rules using the fuzzy linguistic variables (fuzzy sets) to perform a process of decision-making systems.

Fuzzy inference systems are used to represent the interdependence between the independent variables (inputs) and dependents (outputs) of a real system. The basis of these systems is a set of fuzzy conditional rules, which must be defined from the same set of assumptions (independent variables), with responses belonging to the same domain (BÁRDOSSY cited by BARBALHO, 2001).

These systems are generally based on a set of rules (knowledge base) type IF-THEN describing the dependence between the linguistic inputs and outputs variables.

According to Barbalho (2001), a fuzzy inference system is based on known values of the input variables, and can make inferences about these data and obtain the values of the output variables. In this case, the rules are inferred in parallel, regardless of the order in which they are held. The interpretation or inference of each rule consists of the evaluation of the foregoing propositions (premises), after which the consequences. The following figure shows the operation of the process. 


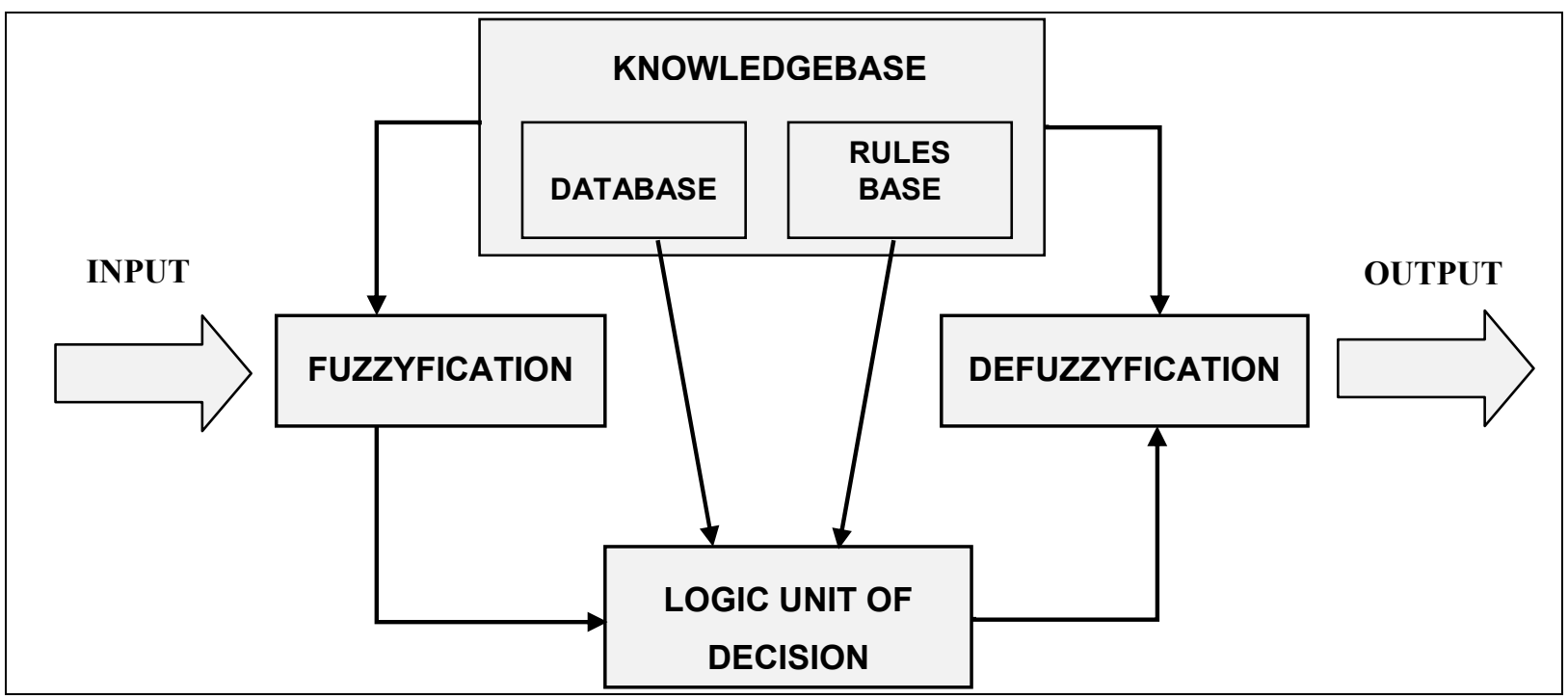

Figure 5: Fuzzy Inference System

\subsubsection{Fuzzyfication}

Fuzzy inference systems work with inaccurate information and / or vague terms of natural language. However, when working with data entry computer systems, these are usually numerical values given to the system.

For example, a system that aims to monitor the conditions of a fuel storage tank and take some action depending on them, using for that, data on temperature and pressure. When data is sent to the system, they inform numerical values of temperature and pressure.

Because fuzzy systems work with linguistic terms, it is necessary to transform these data into fuzzy sets. Therefore, a mapping is performed of the input data (generally discrete numbers) on fuzzy numbers. It is the process of fuzzyfication.

So in this transformation, the numerical data values for each input variable are modeled with membership functions associated with the corresponding variable, and its resulting degree of membership of each value in the corresponding linguistic terms (BARBALHO, 2001).

In the above example, the value of $35^{\circ} \mathrm{C}$ temperature of the input variable to be converted can be represented by the standard value cloudy and have a degree of relevance, for example, 0.7 , associated with it. 


\subsubsection{Inference Process}

The process of inference, also called logical decision-making, is responsible for evaluating the input variables by applying the rules of the knowledge base and assigning responses to processing. It consists of three stages: Evaluation of Assumptions; Implication; Aggregation and Consequences.

After the fuzzyfication of input variables, the fuzzy rules are evaluated one by one and calculate the degrees of relevance of each proposition. Each combination of propositions (each rule) is applied to a function (the logical operator is used depending on the combination of propositions) to produce a number between 0 and 1 that represents the degree to which the conditional expression of the rule is satisfied (degree of applicability of the rule).

The functions most commonly applied in this process are: the maximum function for the operator "OR", and the function minimum, the operator "AND". This step is the evaluation of assumptions.

According to Barbalho (2001), the implication is used to calculate the consequences of the rules which conditions are satisfied to some degree, based on their degree of applicability. In cases where the rules have more than one result, all consequences are equally affected by the degree of applicability.

When the fuzzy inference system treats the input variables and verifies the rules, generally, is more than one applicable rule. However, it is necessary to generate a single response for each output variable. Aggregation Consequents consists of aggregate, or combine, the consequences of those obtained by inference rules (BARBALHO, 2001). Most often, this aggregation is done using the function maximum which corresponds to the union of fuzzy sets.

\subsubsection{Defuzzyfication}

After the process of fuzzy inference, a fuzzy set answer is obtained, but often this is good not enough for the system response, the system user has difficulties for understanding it. A more appropriate numerical representation of a fuzzy response is required. It is the deffuzzyfication process. 
Taking again the example of the system that monitors the fuel tank. At some point, the fuzzy response must be transformed into a discrete number that represents the activation of the alarm, for example.

Barbalho (2001) presents the schemes of numerical representation of fuzzy sets most commonly used:

- First of Maxima: selects the first element among those that have the maximum degree of membership.

- Last of Maxima: selects the last element among those that have the maximum degree of membership.

- Maximum Average: calculates the average of the elements that has the maximum degree of membership.

- Centroid: choose the central element (center of gravity) of the fuzzy set defined area.

\section{EDUCATIONAL APPLICATIONS}

Troubleshooting as transmission of concepts and assessing learning is widely used. Therefore, a tool like this could not fail to be present in intelligent tutoring systems.

For an ITS to work with problem solving, it is important to adopt a database of problems (solutions containing both the teachers and the solutions obtained by the students). From these databases of problems, the system will need to propose problems for the learner, based on the students' level of expertise in the subject matter covered, their preferences and level of difficulty of the problem. It is also necessary that the system has mechanisms to assess problems solved. These assignments fit to an agent (assistant troubleshooting) ITS.

This agent, through communications with the tutor agent acquires the necessary information about the student, such as knowledge level, personal preferences; subject addressed, among others, and is better able to offer consistent problems with the reality of the learner.

The task of evaluating these issues is made using fuzzy logic. This, through information and level of difficulty of the problem, knowledge level of the student input 
DOI: 10.14807/ijmp.v6i2.250

variables and data of the problem, among others will be able to infer a concept for the problem solved or even apply a grade.

\section{CONCLUSIONS}

It is almost unanimously asserted that a country is able to develop through investing in education. It is therefore important to develop tools to help in the educational process. Research in this area has grown significantly in recent years. All contributions are important for the development of effective education systems.

The applications of fuzzy logic in the field of education are quite promising. Integrating it with other techniques of artificial intelligence technologies is making the traditional and distance learning increasingly adaptable to the needs of students. This reality will increasingly allow for a quality education which is student-centered, and without borders.

\section{BIBLIOGRAPHY}

BARBALHO, V. M. S (2001). Sistemas baseados em conhecimento e lógica difusa para simulação do processo chuva-vazão. Thesi (PhD in Civil Engeneering). Rio de Janeiro: Universidade Federal do Rio de Janeiro.

COSTA, A.; RODRÍGUEZ, A.; SIMAS, E.; ARAÚJO, R (2003). Lógica fuzzy: conceitos e aplicações. In: WORKSHOP DE SOFTWARE LIVRE, 4, Porto Alegre. Proceedings... Porto Alegre, 2003. Avaiable:

<http://www.inf.unisinos.br/ cazella/dss/fuzzy_relatorio.pdf>. Acess: 16th December, 2013.

Fowler, D. G., (1991). A Model for Designing Intelligent Tutoring Systems. Journal of Medical Systems, Vol. 15, N. 1.

Hsieh, T.-C., Wang, T.-I., Su, C.-Y., \& Lee, M.-C. (2012). A Fuzzy Logic-based Personalized Learning System for Supporting. Adaptive English Learning. Educational Technology \& Society, 15 (1), 273-288.

JONASSEN, D.H.,WANG, S. (1993). The Physics Tutor: Integrating Hypertext and Expert Systems. Journal of Educational Technology Systems, Vol. 22, pp. 1928.

Oliveira JR, H.; Caldeira, A. M.; Machado, M. A. S.; Souza, R.; Tanscheit, R., Inteligência Computacional Aplicada à Administração, Economia e Engenharia em Matlab. Rio de Janeiro, Thompson, 2007.

PARK, O.; PEREZ, S.; SEIDEL, F. J (1987). Intelligent CAI: Old Wine in New Bottles or a New Vintage?, in: KEARSLEY, G., Artificial Intelligence and Instruction Applications and Methods, p. 11-45.

POZZEBON, E.; BARRETO, J (2002). Inteligência artificial no ensino com tutores inteligentes. Revista de divulgação científica e cultural. Revista da Editora da 
UINIPLAC, v. 5, n. 1, pág 141-162. Available:

<http://www.das.ufsc.br/ eliane/artigos/pozzebon02l.pdf>. Acess: 13th June, 2013.

PANJAITAN, Seno D. \& HARTOYO, Aryanto (2011). A Lighting Control System in Buildings based on Fuzzy Logic. TELKOMNIKA, Vol.9, No.3, December 2011, p. 423-432.

PIAGET, Jean. Estudos Sociológicos. São Paulo: Editora Forense,1973.

ROSS, Timothy J. Fuzzy logic with engineering applications. Chichester: Timothy J. Ross, 3 ed, 2010.

SCHMITZ, A.; LÓPEZ, O.; FARACO, R.; ROSATELLI, M (2002). Ferramenta de autoria de sistema tutores inteligentes construindo o modelo do domínio do conhecimento com redes semânticas. In: CONGRESSO BRASILEIRO DE COMPUTAÇÃO, 2, Vale do Itajaí. Proceedings... Vale do Itajaí, 2002. Avaiable: <http://www.cbcomp.univali.br/pdf/2002/ine012.pdf>. Acess: 15th July, 2013.

SHAW, Ian S.; SIMÕES, Marcelo G. Controle e Modelagem Fuzzy. São Paulo: Edgard Blücher, 1999.

SICHMAN, J. et. al. When can Knowledge-Based Systems be called agents? In: SIMPÓSIO BRASILEIRO DE INTELIGÊNCIA ARTIFICIAL, 9., 1992, Rio de Janeiro. Anais... Rio de Janeiro: SBC, 1992. p. 172-185.

SINGH, Harpreet, et. al. (2013). Real-Life Applications of Fuzzy Logic. In: Advances in Fuzzy Systems. Vol. 2013.

VALENTE, J. A (1997). O uso inteligente do computador na educação. Pátio Revista da Editora Artes Médicas Sul, v. 1, n 1, p.10-21. 